\title{
A New Approach to Identifying Crash Hotspot Intersections (CHIs) Using Spatial Weights Matrices
}

\author{
Zhonggui Zhang ${ }^{1,2,3}$, Yi Ming ${ }^{4}$ and Gangbing Song ${ }^{3, *(1)}$ \\ 1 School of Architecture and Materials Engineering, Hubei University of Education, Wuhan 430205, China; \\ zzhang66@uh.edu \\ 2 Hubei BIM Smart Construction International Science \& Technology Cooperation Base, Wuhan 430205, China \\ 3 Department of Mechanical Engineering, University of Houston, Houston, TX 77204, USA \\ 4 Department of Information System, Arizona State University, Tempe, AZ 85281, USA; yming2@asu.edu \\ * Correspondence: gsong@uh.edu
}

Received: 25 January 2020; Accepted: 26 February 2020; Published: 29 February 2020

check for updates

\begin{abstract}
In this paper we develop a new approach to directly detect crash hotspot intersections (CHIs) using two customized spatial weights matrices, which are the inverse network distance-band spatial weights matrix of intersections (INDSWMI) and the k-nearest distance-band spatial weights matrix between crash and intersection (KDSWMCI). This new approach has three major steps. The first step is to build the INDSWMI by forming the road network, extracting the intersections from road junctions, and constructing the INDSWMI with road network constraints. The second step is to build the KDSWMCI by obtaining the adjacency crashes for each intersection. The third step is to perform intersection hotspot analysis (IHA) by using the Getis-Ord Gi* statistic with the INDSWMI and KDSWMCI to identify CHIs and test the Intersection Prediction Accuracy Index (IPAI). This approach is validated by comparison of the IPAI obtained using open street map (OSM) roads and intersection-related crashes (2008-2017) from Spencer city, Iowa, USA. The findings of the comparison show that higher prediction accuracy is achieved by using the proposed approach in identifying CHIs.
\end{abstract}

Keywords: crash hotspot intersections (CHIs); road network; traffic crash; spatial weights matrix (SWM); Getis-Ord Gi*; hotspot analysis; Intersection Prediction Accuracy Index (IPAI)

\section{Introduction}

The nation's transportation infrastructural systems are deteriorating [1] under adverse influences from multiple factors, such as corrosion [2,3], aging [4], impact [5,6], and vibration [7], and even with the recent advances in structural health monitoring [8-10] and intelligent transportation systems [11,12], traffic crashes still happen. The latest quick facts report from the National Highway Traffic Safety Administration indicates that there were 2,746,000 people injured in 6,452,000 police-reported crashes in 2017 in the USA [13]. As junctions of traffic flow and pedestrian flow, intersections with ancillary facilities have an important impact on the frequency of crashes. Intersection-related crashes, which account for a large portion of all crashes, need more research attention. For example, Iowa, USA, saw about 225,185 intersection-related crashes, about $40.41 \%$ of all crashes, from 2008 to 2018 [14]. Given the fact of the massive number of intersections, identifying crash hotspot intersections (CHIs) is an important but challenging task.

A review of previous studies shows that the Getis-Ord $\mathrm{Gi}^{*}$, well known in hotspot analysis, has been commonly used to detect crash hotspots [15]. Hotspot analysis examines the Getis-Ord Gi* statistic [16,17], a local indicator of spatial autocorrelation developed by Professor Arthur Getis and J. Keith Ord, for individual crashes based on a comparison with neighboring crashes to quantitatively 
describe crashes and hotspot areas where crashes are mainly concentrated. Ouni et al. [18] discussed the identification of hot zones and enhanced the capability to examine a given highway by determining dangerous segments. Khan et al. [19] used the Getis-Ord Gi* statistic to analyze weather-related crashes which occurred in adverse weather conditions. Prasannakumar et al. [20] assessed the spatial clustering of accidents and hotspots' spatial densities using the Getis-Ord $\mathrm{Gi}^{*}$ statistic. Erdogan et al. [21] compared traditional hotspot detection methods with spatial statistical methods, including the Getis-Ord Gi* statistic, in terms of their sensitivity to spatial characteristics of crash clusters. Kuo et al. [22] combined kernel density estimation and Getis-Ord Gi* maps to identify high-risk areas for traffic crash hotspots and crime events. Zahran et al. [23] presented a new method to evaluate the application of four different hotspot analysis methods, such as Getis-Ord Gi* , in ArcGIS 10.2 to identify and rank hotspots using historical data on a section of a road in Brunei Darussalam. Memisoglu [24] et al. used hotspot analysis (Getis-Ord $\mathrm{Gi}^{*}$ ) and the kernel density method to identify traffic accident hotspots for traffic safety.

The above studies focused on using the Getis-Ord $\mathrm{Gi}^{*}$ statistic to identify crash hotspots. Unlike crash hotspot analysis, only a limited number of studies have been dedicated to analyzing the spatial relationships between intersections and traffic crashes. Mitra [25] indicated that unstructured effects were somewhat significant at the intersection level for cases of severe-injury crashes. Cheng et al. [26] presented a crash evolution characteristic analysis for identifying hotspots among Wujiang's road intersections. Cinnamon et al. [27] examined the potential associations between violations made by pedestrians and motorists at intersections.

Furthermore, the results of hotspot analysis using the Getis-Ord Gi* statistic in the above research were determined using critical input spatial weights matrices (SWMs) $[28,29]$. The related theories of general SWMs, such as contiguity-based SWMs [30,31], distance-band SWMs [32,33], and k-nearest neighbor SWMs [34], have been widely discussed. However, the general SWMs, which are designed for plane space, cannot provide good support for hotspot analysis in road network space. Therefore, we should improve the construction algorithms and build customized SWMs based on the above general SWM to adapt the identification approach of CHIs. The above studies provide a foundation for this research. However, previous studies neglected some issues in using hotspot analysis. First, these studies mainly focused on the crashes essentially as a phenomenon related to roads or intersections, and could not directly identify CHIs. Second, often the Euclidean distance was used to calculate the weights, neglecting road network restrictions, which may affect the accuracy of the result of hotspot analysis.

To solve these issues, first, we take intersections instead of crashes as the research object, which can directly identify CHIs. Second, the inverse network distance-band spatial weights matrix of intersections (INDSWMI) and the k-nearest distance-band spatial weights matrix between crash and intersection (KDSWMCI) are developed and applied to hotspot analysis to improve the accuracy of the results of $\mathrm{CHI}$ identification. The main tasks of this study include (a) creating the INDSWMI with respect to road network restraints; (b) building the KDSWMCI based on the k-nearest neighbors and distance-bands by obtaining the adjacency crashes and the number of crashes at each intersection; (c) testing the Intersection Prediction Accuracy Index (IPAI) of the proposed approach and identifying the CHIs to help safety researchers develop safety strategies to reduce crashes.

The rest of the paper is organized as follows. Section 2 presents the methodology developed in this paper. Section 3 describes the original data, including the road network and traffic crashes of Spencer city, Iowa. Section 4 illustrates and discusses the results by applying the proposed methodology to Spencer city, Iowa. Finally, Section 5 concludes the paper and recommends future work. 


\section{Methodology}

\subsection{Process Map}

This paper presents a three-step approach to directly identifying crash hotspot intersections (CHIs) by using (1) construction of the inverse network distance-band spatial weights matrix of intersection (INDSWMI), (2) construction of the k-nearest distance-band spatial weights matrix between crash and intersection (KDSWMCI), and (3) intersection hotspot analysis (IHA). The process map for the approach is shown in Figure 1.

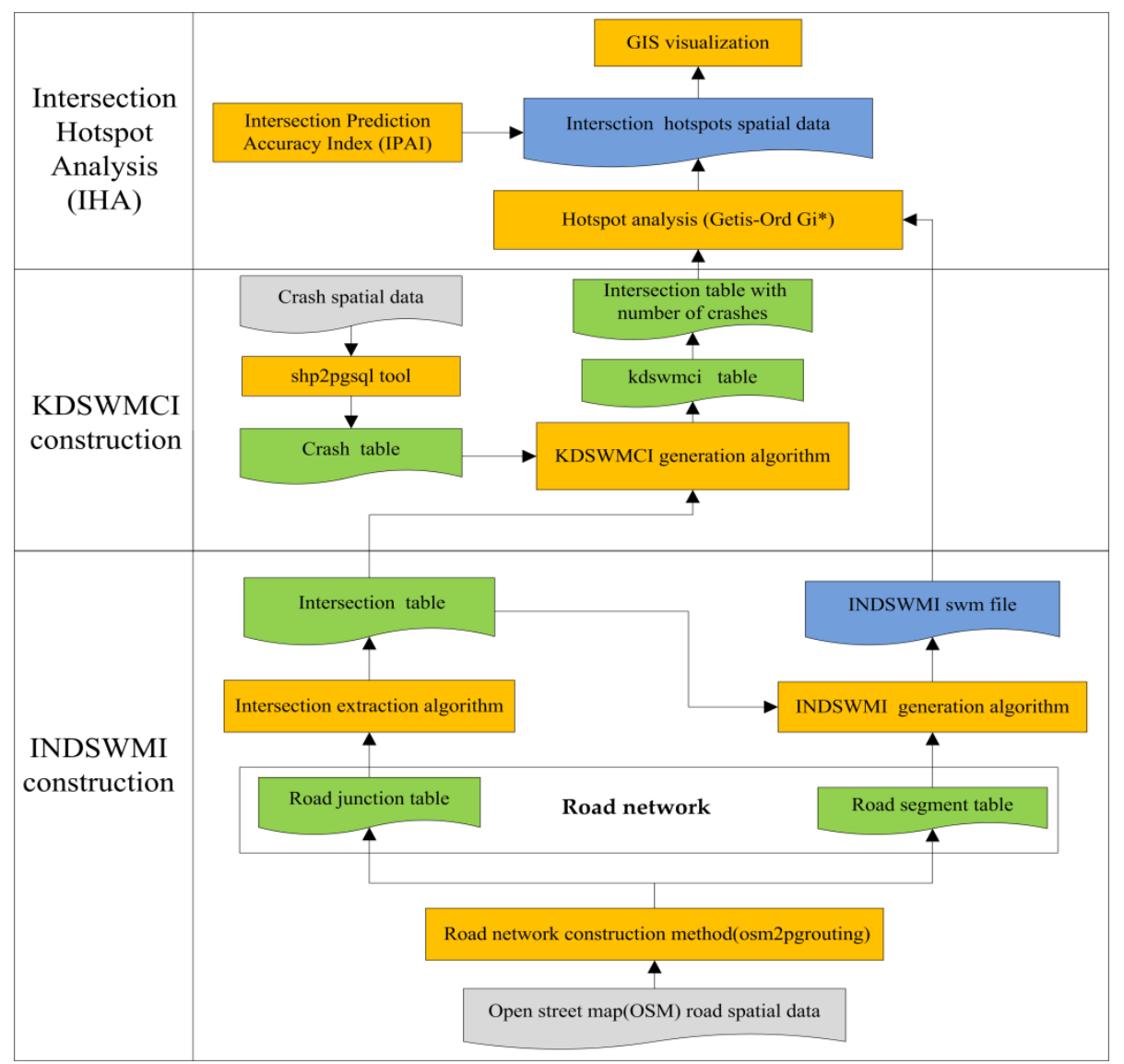

Figure 1. A process map for the identification approach to detect crash hotspot intersections (CHIs).

(1) INDSWMI construction

The first step (INDSWMI construction) includes the following three substeps:

(a) Road network construction. In this research, we apply osm2pgrouting [35], an open source software product, to build the road network including road junction and segment tables from the open street map (OSM) [36] road spatial dataset.

(b) Intersection extraction. Note that a road junction that links with three or more road segments is considered an intersection, which is a junction of traffic flow and pedestrian flow $[37,38]$ in this research. We developed an intersection extraction algorithm to extract intersections, such as T-intersection, Y-intersections, cross-intersections, and X-intersections [39], from the road junction table and create the intersection table. The intersection extraction algorithm can be described as the following structured query language (SQL) script:"create table public.intersection as select * from public.road_junction a where a.degree $>2$ ".

(c) INDSWMI construction. We developed the INDSWMI generation algorithm to construct the INDSWMI, which can conceptualize the spatial relationships between intersections, with road 
network constraints based on the intersection table and road segment table. The INDSWMI is saved in the swm file format which is compatible with ArcGIS.

\section{(2) KDSWMCI construction}

The second step (KDSWMCI construction) is to conceptualize the crash-intersection spatial relationships. We developed the KDSWMCI generation algorithm to calculate the number of crashes and adjacency crashes of each intersection and save the crash-intersection spatial relationships in the KDSWMCI table.

(3) Intersection hotspot analysis

The third step, intersection hotspot analysis, is to identify CHIs using a statistical variable-Getis-Ord $\mathrm{Gi}^{*}$. The intersection hotspot analysis (IHA) generates the intersection hotspots shapefile using the standardized Getis-Ord $\mathrm{Gi}^{*}$ of each intersection under randomization null hypothesis [40] computation. We can detect CHIs through geographic information system (GIS) visualization of the intersection hotspots shapefile. The Intersection Prediction Accuracy Index (IPAI) was calculated to quantitatively evaluate the prediction performance of IHA.

\subsection{Data Types}

There are three types of data in this approach: (1) the input data, (2) the intermediate data, and (3) the output data, as shown in Table 1.

Table 1. An overview of data types.

\begin{tabular}{|c|c|c|c|c|}
\hline Name & Type & File Format & Feature Type & Description \\
\hline OSM Road & Input & osm & Line/Point/Region & $\begin{array}{c}\text { Widely used open access geographic } \\
\text { data }\end{array}$ \\
\hline Crash & Input & shapefile & Point & The geographic data of crashes \\
\hline Road junction & Intermediate & $\begin{array}{l}\text { PostGreSQL } \\
\text { Table }\end{array}$ & Point & $\begin{array}{l}\text { The road junction spatial table } \\
\text { generated } \\
\text { by osm2pgrouting software }\end{array}$ \\
\hline Road segment & Intermediate & $\begin{array}{l}\text { PostGreSQL } \\
\text { Table }\end{array}$ & Line & $\begin{array}{c}\text { The road segment spatial table } \\
\text { generated } \\
\text { by osm2pgrouting software }\end{array}$ \\
\hline Crash table & Intermediate & $\begin{array}{l}\text { PostGreSQL } \\
\text { Table }\end{array}$ & Point & $\begin{array}{l}\text { The crash spatial table converted } \\
\text { by shp2pgsql tool }\end{array}$ \\
\hline Intersection & Intermediate & $\begin{array}{l}\text { PostGreSQL } \\
\text { Table }\end{array}$ & Point & $\begin{array}{l}\text { The intersection spatial table with } \\
\text { number of crashes } \\
\text { extracted from road junction }\end{array}$ \\
\hline KDSWMCI table & Intermediate & $\begin{array}{l}\text { PostGreSQL } \\
\text { Table }\end{array}$ & / & $\begin{array}{l}\text { Stores the crash-intersection spatial } \\
\text { relationships }\end{array}$ \\
\hline INDSWMI file & Output & SWM & I & $\begin{array}{l}\text { SWM format file with INDSWMI info } \\
\text { from ArcGIS }\end{array}$ \\
\hline $\begin{array}{l}\text { Crash hotspot } \\
\text { intersections }\end{array}$ & Output & Shapefile & Line & $\begin{array}{l}\text { The result of intersection hotspot } \\
\text { analysis }\end{array}$ \\
\hline
\end{tabular}

\subsubsection{The Input Data}

Two data sets are required as the inputs for this approach: the OSM road data and the crash shapefile. The OSM road data should contain the geometric info (a list of point coordinates) and the "highway" attribute. Note that "highway" in British English is used to indicate any type of road, such as motorway, primary, route, footway, and pedestrian, within OSM. In this research, we selected only the highways for cars, such as motorway, primary, secondary, tertiary, residential, and service, since we focused on traffic intersections. The crash shapefile should contain the geometric info (x-coordinate, $\mathrm{y}$-coordinate) that is used to locate crashes on intersections. Crash-related factors [41,42], such as environment and driver, and crash attributes, such as crash type and date, are not necessary but are suggested. 


\subsubsection{The Intermediate Data}

Intermediate files include a series of tables, such as crash, road junction, road segment, KDSWMCI, and intersection tables. The crash table was converted by using the shp2pgsql tool. The road junction and road segment tables, generated by osm2pgrouting software, contain the topological information and form of the road network. Note that the osm2pgrouting software cannot generate the intersection table. We developed an intersection extraction algorithm to build the intersection table with attributes such as the degree and type based on road network topological information.

In this research, we used PostGreSQL [43], a widely used open source database management system (DBMS), and PostGIS [44], an open source geospatial engine for PostgreSQL, to store and query spatial data of roads, intersections, and crashes. The geometry and attributes of the above tables were inherited from the input OSM road data and crash shapefile.

\subsubsection{Output Results}

The INDSWMI file and intersection hotspot shapefile are the output results. The INDSWMI file is constructed based on the network distance of intersections to conceptualize the intersection spatial relationships as a foundation for IHA. To improve the effectiveness of the approach, we used the binary swm file format, which is compatible with ArcGIS [45], to store INDSWMI data. Each row in a binary swm format file is formatted into four columns: OBJECTID (row index), GID (the ID of intersection $i$ ), NID (the ID of intersection $j$ ), and WEIGHT (the spatial weight between intersection GID and NID). The intersection hotspot shapefile, the result of the IHA (Getis-Ord $\mathrm{Gi}^{*}$ ), contains the hotspot intersections, coldspot intersections, and non-significant intersections. The hotspot intersections are the results that we should identify in this research.

\subsection{Methods}

\subsubsection{The INDSWMI Generation Algorithm}

A spatial weights matrix (SWM), the conceptualization of spatial relationships between features [46], is the key input parameter for hotspot analysis. The SWMs can be mainly divided into contiguity-based spatial weights matrices (CSWMs) and distance-band spatial weights matrices (DSWMs). The CSWM, which expresses the existence of a neighbor relation as a binary value, 1 or 0 , is widely used in region-based hotspot analysis [47]. The DSWM, which expresses the spatial relationships as distance weights [48], is intrinsically most appropriate for point-based hotspot analysis. We adopted the DSWM to express the spatial relationships between intersections since intersections are a typical point feature.

The inverse network distance-band spatial weights matrix of intersections (INDSWMI) based on the DSWM is an $\mathrm{N} \times \mathrm{N}$ matrix. Generally, $W_{i j}$ is defined using inverse Euclidean distance measurement. However, intersections are constrained by the road network, which has complex topological and geometric relationships [49]. The inverse network distance along the road is more appropriate for the measurement of $W_{i j}$ of the INDSWMI, which is defined as

$$
W_{i j}= \begin{cases}1 / n d_{i j}, & n d_{i j} \leq \text { distance band } \\ 0, & n d_{i j}>\text { distance band }\end{cases}
$$

where the distance band is a cutoff distance that can be specified in accordance with the minimum number of neighbors of each intersection (the minimum number of neighbors is 1 in this research according to the suggestion of Getis and Aldstadt [29]); $n d_{i j}$ is the network distance between intersections 
$i$ and $j$. If $n d_{i j}$ is less than or equal to the distance band, then $W_{i j}=1 / n d_{i j}$ (reverse network distance); otherwise, $W_{i j}=0 . n d_{i j}$ is expressed as

$$
n d_{i j}=\sum_{k=1}^{n} \operatorname{length}\left(r_{k}, r_{k} \in \operatorname{sp}\left(I_{i}, I_{j}\right)\right)
$$

where $s p\left(I_{i}, I_{j}\right)$ is the shortest path set of intersections $i$ and $j$, calculated by Dijkstra's algorithm [50], and contains a series of road segments $\left(r_{k}\right) ; n d_{i j}$ is the total length of road segments within $s p\left(I_{i}, I_{j}\right)$.

Note that row standardization of $W_{i j}$ is suggested to create proportional weights in cases where intersections have an unequal number of neighbor intersections [29]. The row-standardized form of $W_{i j}$ for hotspot analysis is expressed as

$$
W_{i j}=\left\{\begin{array}{l}
\frac{1 / n d_{i j}}{\sum_{j=1}^{n} 1 / n d_{i j}}, \quad n d_{i j} \leq \text { distance band } \\
0 \quad, \quad n d_{i j}>\text { distance band }
\end{array}\right.
$$

Based on Equations (1) and (2), we used the qt framework [51], an open source cross-platform, to develop the INDSWMI generation algorithm with PostGreSQL/PostGIS. Figure 2 shows the definitions of the main data types: intersection, network distance of intersections (NDI), network distance matrix of intersections (NDMI), spatial weight of intersections (SWI), and INDSWMI.

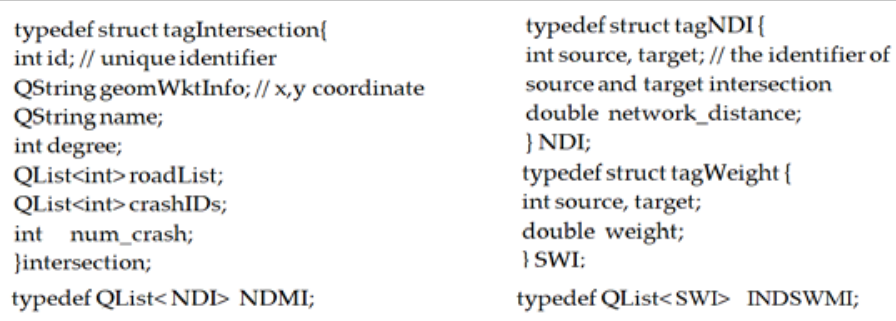

Figure 2. Definition of main data types of the INDSWMI generation algorithm.

Using the main data types, we developed a five-step algorithm with pseudocode shown in Figure 3 to generate the INDSWMI. The five steps are to (1) connect to the PostGreSQL/PostGIS database; (2) cache the intersection table in the PostGreSQL/PostGIS database to memory; (3) build the NDMI using the pgr_dijkstra fuction provided by the pgrouting extension for the PostGreSQL/PostGIS database; (4) generate the INDSWMI based on the NDMI restricted by the distance band; and (5) save the INDSWMI to the swm file format. 


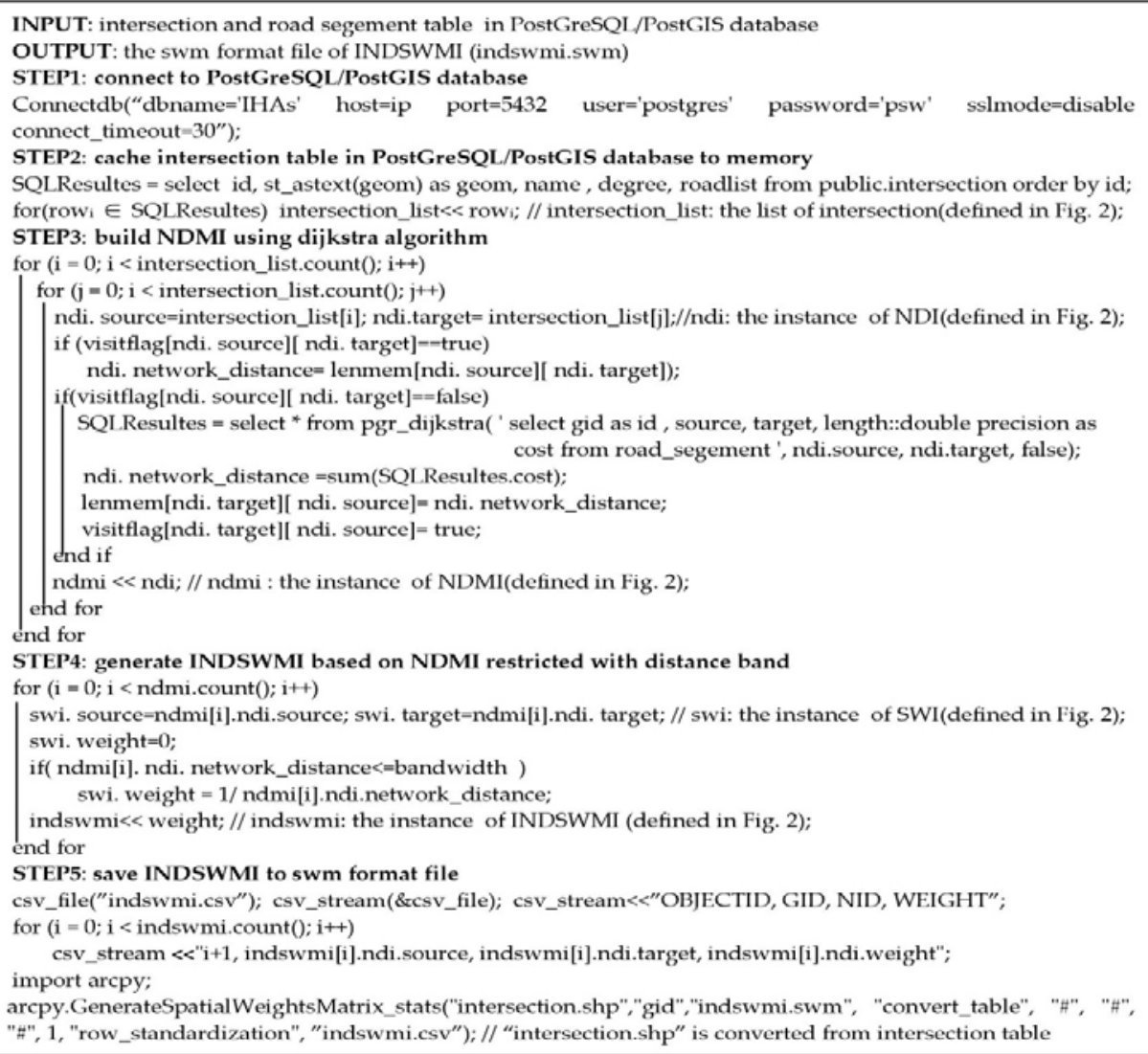

Figure 3. The INDSWMI generation algorithm.

\subsubsection{The KDSWMCI Generation Algorithm}

To identify the crash hotspot intersections (CHIs), we should build the k-nearest distance-band spatial weights matrix between crash and intersection (KDSWMCI, $\mathrm{k}=1$ ) based on CSWM by obtaining the adjacency crashes and the number of crashes at each intersection.

Generally, an SWM is an $N \times N$ matrix whose elements are spatial weights. In this research, we expanded the SWM to an $\mathrm{M} \times \mathrm{N}$ matrix, as shown in Equation (4), which can accommodate different numbers of intersections and crashes. There is one row for each intersection and one column for each crash.

$$
\text { KDSWMIC }=\begin{array}{ccccc} 
& 1 & 2 & j & n \\
1 & w_{11} & w_{12} & w_{1 j} & w_{1 n} \\
2 & w_{21} & w_{22} & w_{2 j} & w_{2 n} \\
i & w_{i 1} & w_{i 1} & w_{i j} & w_{i n} \\
m & w_{\mathrm{m} 1} & w_{m 2} & w_{m j} & w_{m n}
\end{array}
$$

Here, $m$ is the number of crashes; $n$ is the number of intersections; $i$ is the unique identifier of a crash; $j$ is the unique identifier of an intersection; and $W_{i j}$ is the weight that quantifies the spatial relationship between crashes and intersections. If crash $i$ occurs on intersection $j$, then $W_{i j}=1$; otherwise, $W_{i j}=0$. We can determine that a crash is on an intersection if the geometric relationships between the crash and intersection meet both of Conditions 1 and 2:

1. Condition 1: The shortest distance between the crash and the intersection is less than or equal to the threshold distance.

2. Condition 2: The intersection-related crash relates to one, and only one, intersection. That means that the k-nearest neighbor is the same as the 1st-nearest neighbor. Therefore, if crash $i$ occurs on 
intersection $j$, then the shortest distance between crash $i$ and intersection $j$ should be the minimum distance in all datasets.

According to Conditions (1) and (2), the weight of the KDSWMCI is expressed as

$$
W_{i j}=\left\{\begin{array}{c}
1, \text { if } d_{i j} \leq \text { threshold } \\
0, \text { distance and } d_{i j} \leq \forall d_{i k} \\
0 \text { else }
\end{array}\right.
$$

where $d_{i j}$ is the Euclidean distance between crash $i$ and intersection $j ; d_{i k}$ is the Euclidean distance between crash $i$ and intersection $k$. A threshold distance of $28.5 \mathrm{~m}$ was selected by considering ten-lane intersections and Global Positioning System (GPS) positioning accuracy according to the following premises:

Premise 1 Crash GPS coordinates have a positioning error of approximately $10 \mathrm{~m}$ [52]. A crash is considered to occur on the intersection if its coordinates are within $10 \mathrm{~m}$ of the buffer of the intersection considering the positioning error.

Premise 2 As the Interstate Highway standards for the U.S. Interstate Highway System use a 12 foot $(3.7 \mathrm{~m})$ standard lane width, a crash occurring on the intersection can be determined if its coordinates are within $(3.7 \times n / 2) \mathrm{m}$ of the buffer of the intersection, where $n$ is the number of lanes of the intersection.

We realized the KDSWMCI generation algorithm based on the qt framework with the PostGreSQL/PostGIS database. Figure 4 shows the definitions of the main data types: crash, spatial weight between crash and intersection (SWCI), and KDSWMCI. Note that the structure of intersections used in the algorithm is defined in Figure 2.

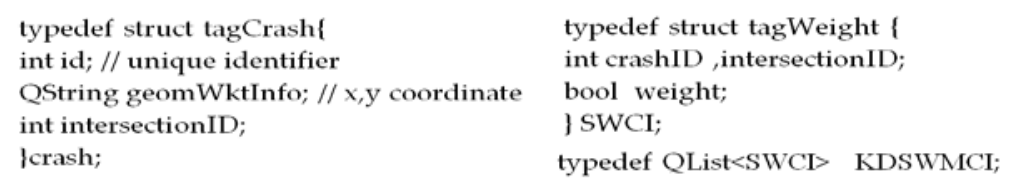

Figure 4. Definition of the main data types of the KDSWMCI generation algorithm.

Based on the main data types, we developed a five-step algorithm with pseudocode shown in Figure 5 to generate the KDSWMCI: (1) connect to the PostGreSQL/PostGIS database; (2) cache the intersection and crash table in the PostGreSQL/PostGIS database to memory; (3) build the KDSWMCI using the st_within function and Euclidean distance measurement provided by the postgis extension for PostGreSQL to determine whether a crash is on an intersection according to Conditions 1 and 2; (4) save the crash-intersection spatial relationships to the KDSWMCI table in the PostGreSQL/PostGIS database; (5) compute the number of crashes for each intersection based on the KDSWMCI table. 
INPUT: the intersection and crash table in PostGreSQL/PostGIS database

OUTPUT: the kdswmci table and the number of crashes for each intersetion STEP1: connect to PostGreSQL/PostGIS database

Connectdb("dbname='IHAs' host=ip port=5432 user='postgres' password='psw' sslmode=disable connect_timeout $\left.=30^{\prime \prime}\right)$;

STEP2: cache intersection and crash table in PostGreSQL/PostGIS database to memory

SQLResultes = select id, st_astext(geom) as geom from public.intersection order by id;

for(rowi $\in$ SQLResultes) intersection_list<< rowi; // intersection_list: the list of intersection(defined in Fig. 2);

SQLResultes = select id, st_astext(geom) as geom from public.crash order by id;

for(rowi $\in$ SQLResultes) crash_list $<<$ rowi; // crash_list: the list of crash (defined in Fig. 4);

STEP3: build KDSWMCI according to condition (1) and (2)

for $(\mathbf{i}=0$; $\mathrm{i}<$ crash_list.count(); $\mathrm{i}++)$

SQLResultes $=$ select id from public.intersection where st_within(intersection.geom, st_buffer(geography(st_geomfromtext(crash_list[i].geomWktInfo)), 28.5)) order by

if( SQLResultes is not null) intersection.geom $<>$ ST_PointFromText(crash_list[i].geomWktInfo,4326) limit 1;

swci. crashID= crash_listt[i].id; // swci: the instance of SWCI (defined in Fig. 4);

swci. intersectionID = SQLResultes[0]; swci.weight=true;

kdswmci<< swci.weight; // kdswmci: the instance of KDSWMCI (defined in Fig. 4);

end if

end for

STEP4: save the crash-intersection spatial relationships to the kdswmci table

for $(\mathrm{i}=0$; $\mathrm{i}<\mathrm{kdswmci}$.count () ; $\mathrm{i}++)$

insert into public. kdswmci (crashID, intersectionID, weight) values

(kdswmci[i].crashID, kdswmci[i].intersectionID, ndmi[i].weight);

end for

STEP5: statistic the number of crashes of each intersection

for $(\mathrm{i}=0$; $\mathrm{i}<$ intersection_list.count ()$; \mathrm{i}++)$

num $=$ select $\operatorname{sum}(*)$ from public.kdswmci where intersectionID= intersection_list[i].id;

update public.intersection set num_crash $=$ num where id = intersection_list[i] $]$.id

end for

Figure 5. The KDSWMCI generation algorithm.

\subsubsection{Intersection Hotspot Analysis (Getis-Ord Gi*)}

The Getis-Ord G, including Getis-Ord General G and Getis-Ord Gi* [16], is one of the preferred measurement techniques for hotspot analysis [53]. The Getis-Ord General G is a single index that can detect the degree of autocorrelation to verify the spatial distribution pattern in the entire spatial extent. The Getis-Ord Gi ${ }^{*}$ is used as a local indicator [54] of spatial autocorrelation in IHA to identify CHIs. The Getis-Ord $\mathrm{G}_{\mathrm{i}}^{*}$ was calculated for each intersection to reveal the degree of spatial autocorrelation and was used to analyze whether the same variable ( $<$ num_crash $>$ in this research) has spatial autocorrelation. The Getis-Ord Gi ${ }^{*}$ is expressed as [16]

$$
G_{i}^{*}=\frac{\sum_{j=1}^{n} w_{i j} x_{j}}{\sum_{j=1}^{n} x_{j}}
$$

where $G^{*}$ is the statistic that expresses the spatial degree of spatial autocorrelation of intersection $i$ with the number of crashes over all neighboring intersections; $W_{i j}$ is the weight in the INDSWMI (discussed in Section 2.3.1) that quantifies the spatial relationship between intersection $i$ and intersection $j ; x_{j}$ is the number of crashes at intersection $j$ (discussed in Section 2.3.2 based on the KDSWMCI); and $n$ is the total number of neighboring intersections.

According to the first law of geography, the number of crashes at an intersection, related to each other in geography, has a spatial distribution pattern that is either dispersed, random, or clustered [55]. The spatial distribution of the $G i^{*}$ statistic is random when randomness is also observed in the underlying distribution of the number of crashes at intersections. However, crashes have a clustered distribution pattern in reality. Therefore, in IHA, it is necessary to make assumptions about the spatial distribution of the number of crashes at intersections, which is the randomization null hypothesis. Testing of the randomization null hypothesis of spatial distribution can be performed based on the 
$z$-score (a standardized statistic) of the $G^{*}$, as shown in Equation (7) [56], along with the $p$-value (a probability value used to express the confidence level).

$$
G_{i}^{*} \text { ZScore }=\frac{\sum_{j=1}^{n} w_{i j} x_{j}-\bar{X} \sum_{j=1}^{n} w_{i j}}{S \sqrt{\frac{\left[n \sum_{j=1}^{n} w_{i j}^{2}-\left(\sum_{j=1}^{n} w_{i j}\right)^{2}\right]}{n-1}}}
$$

Here, Gi ${ }^{*}$ ZScore is the standardized $G i^{*}$ value of intersection $i$. The $G i^{*} Z S c o r e s$ are measures of statistical significance which inform us whether or not to reject the randomization null hypothesis, intersection by intersection. In this study, $p$-values of $\leq 0.05$ (95\% confidence level) were used to indicate different levels of significant clusters, which were applied to each intersection. To be more specific, if an intersection's $p$-value was $>0.05$ and its $G i^{*} Z S$ core was $>1.96$ [57], that intersection was considered a hotspot intersection at the $95 \%$ confidence level. $W_{i j}$ is the weight in the INDSWMI, $x_{j}$ is the number of crashes at intersection $j$ calculated in the KDSWMCI, and $\bar{x}$ is the average number of crashes at all neighboring intersections. $S$ is related to the measurement of sample variance and is defined as [56]

$$
\bar{X}=\frac{\sum_{j=1}^{n} x_{j}}{\mathrm{n}} S=\sqrt{\frac{\sum_{j=1}^{n} x_{j}{ }^{2}}{n}-(\bar{X})^{2}} .
$$

\subsubsection{The Intersection Prediction Accuracy Index (IPAI)}

Evaluation of hotspot analysis prediction performance is an important issue relating to the suitability of this proposed approach. The Prediction Accuracy Index (PAI) [58], firstly proposed by Chainey et al., is the ratio of the hit rate to the fraction of area covered [59]. The PAI has been widely applied to measure hotspot analysis results [17,59-61]. Previously, the Crash Prediction Accuracy Index (CPAI) was developed by using road length rather than area for evaluating traffic crash hotspot analysis performance $[17,61]$. Based on the previous studies, the Intersection Prediction Accuracy Index (IPAI) was developed in this research with road network restraints for evaluating IHA prediction performance as follows:

$$
I P A I=\frac{\sum_{j=1}^{m} x j, j \in H I / \sum_{i=1}^{n} x i, i \in I}{\sum_{i=1, j=1}^{m} l s p(i, j) / \sum_{i=1}^{r} l i, i \in R}
$$

where $H I$ is the set of hotspot intersections; $I$ is the set of all intersections in the study region; $R$ is the set of all roads in the study region; $m, n$, and $r$ are the number of $H I, I$, and $R$, respectively; $x_{j}$ is the number of crashes of intersection $j$ within $H I ; x_{i}$ is the number of crashes at intersection $i$ within $I$; $s p(i, j)$ is the shortest path set between intersections $i$ and $j$ within HI; $l_{s p(i, j)}$ is the total length of the shortest path set; and $l_{i}$ is the length of road $i$ within $I$. Note that a road can be in any shortest path only once and cannot be duplicated. IPAI is an indicator to quantify the prediction performance of IHA. The total length of road and the total number of crashes in the study region are constants. That is, the higher the IPAI which means that the larger number of crashes in CHIs while the shorter lengths of shortest paths between CHIs, the better the prediction performance of the approach.

\section{Original Data}

More than $50 \%$ of the population of United States live in small cities and towns [62]. Small cities have been ignored by researchers. This negligence of smaller cities has profound consequences for urban studies [62]. Additionally, in fact, megacities are usually composed of several small cities. Indeed, research identifying CHIs in small cities is meaningful and important. Therefore, Spencer city, 
Iowa, United States-a small city-was selected for evaluation of the proposed approach. Spencer covers an area of approximately $28.96 \mathrm{~km}^{2}$. We considered roads for cars, such as motorway, primary, secondary, tertiary, residential, and service roads, and crashes which occurred on intersections within the Spencer city boundary.

\subsection{The Road Network}

The raw input OSM roads employed in this study can be downloaded from the OSM website (https://www.openstreetmap.org). Firstly, we exported the spatial data of all types of roads in the osm file format using an enveloping rectangle [43.1974, -95.1108, 43.1043, and 95.201] of the study area. Secondly, we applied the osm2pgrouting tool to select the roads for cars and built the road network in the PostGreSQL/PostGIS database. Thirdly, we used the ST_Intersects function provided by the PostGIS extension to clip the roads within the Spencer city boundary, which can be downloaded from OSM Boundaries 4.6.4 (https://wambachers-osm.website/boundaries/). A total of 2081 road segments for cars and 1456 junctions were successfully selected, as shown in Figure 6.

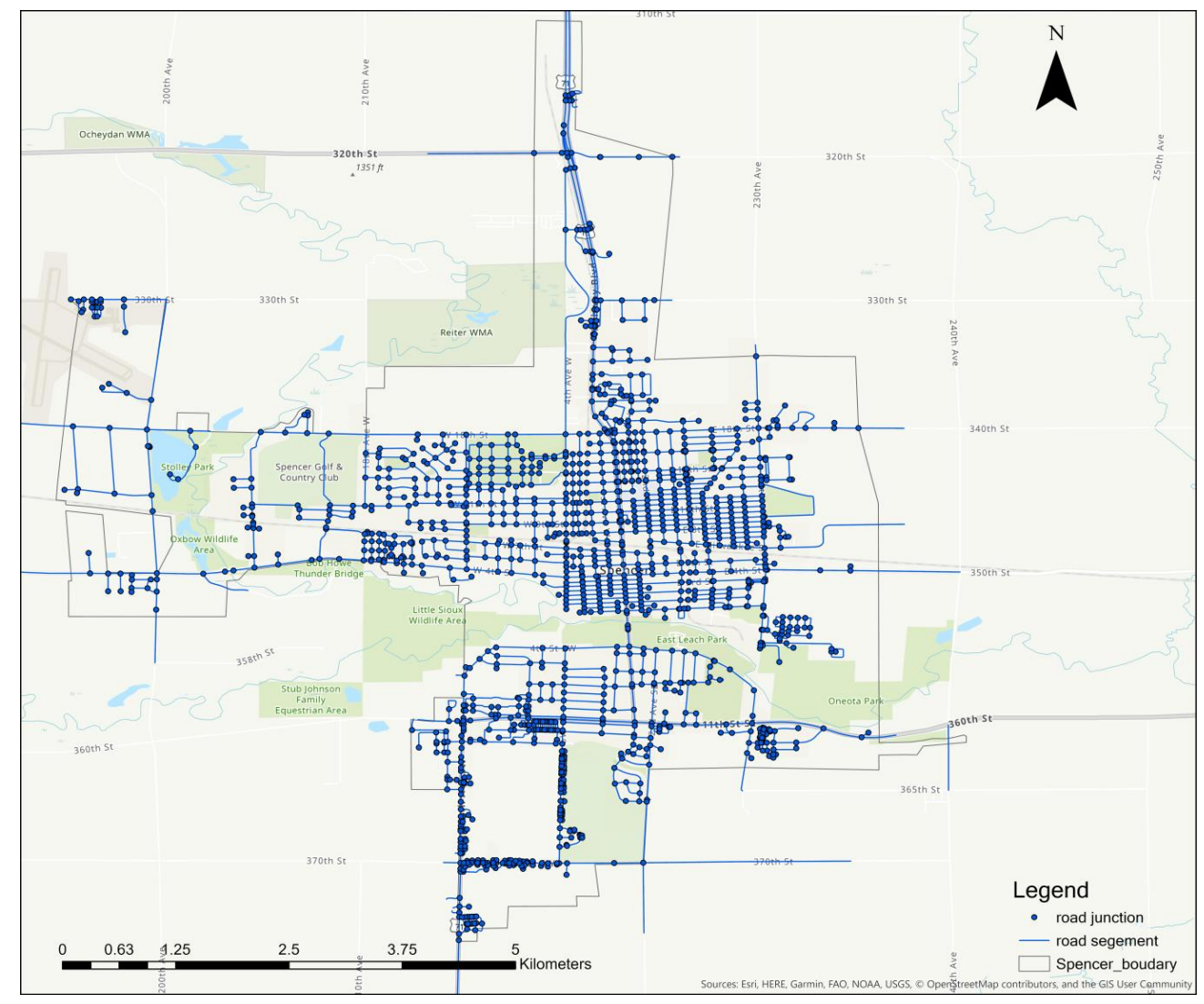

Figure 6. Distribution of the road network in Spencer city.

Note that intersections should be extracted from road junctions since junctions are not always intersections. A total of 1065 intersections in Spencer city were selected using the intersection extraction algorithm (discussed in Section 2.1), as shown in Figure 7. 


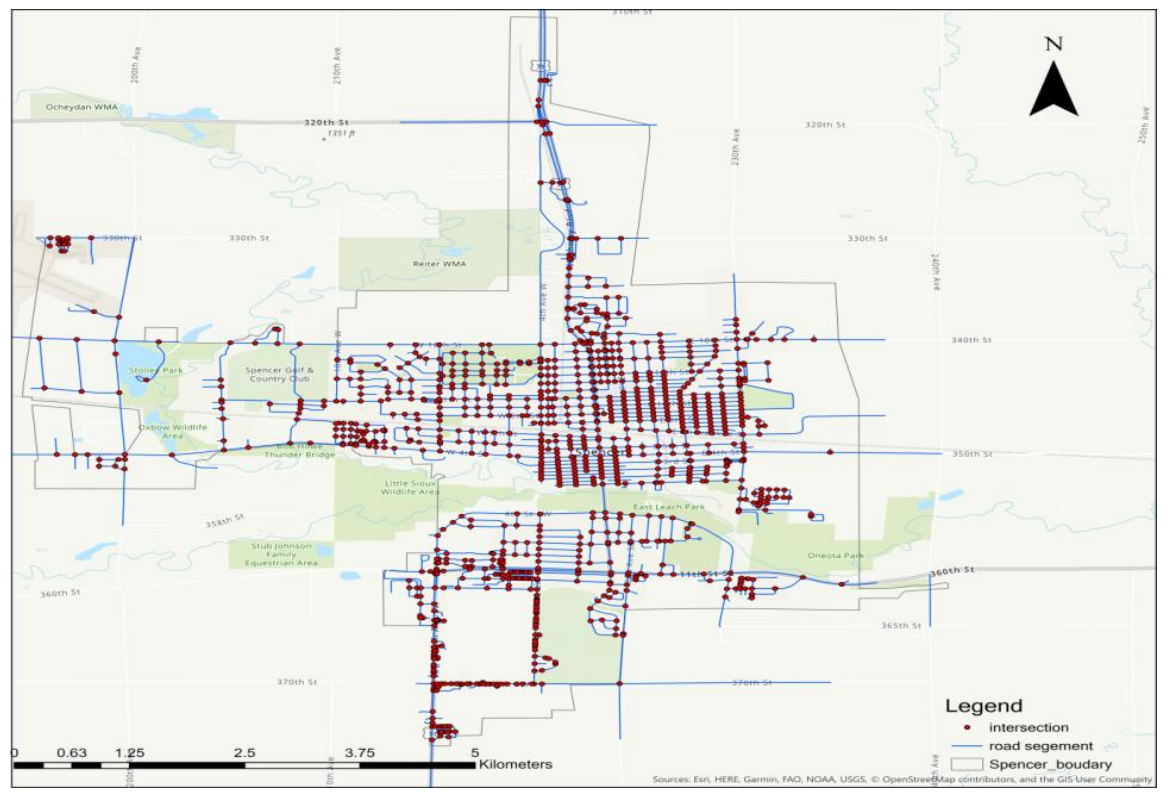

Figure 7. Distribution of intersections in Spencer city.

\subsection{Intersection-Related Crashes}

We employed the spatial data of crashes provided by the Iowa Department of Transportation's public platform (https://data.iowadot.gov/), which has statewide data of general traffic crashes from the previous 10 years. The crash data contain 49 types of information (e.g., crash_date, district, county_num, literal, light, weather, rdtype, xcoord, and ycoord) and met the requirements of this research. For this research, a dataset of intersection-related crashes that occurred in Spencer city was selected and analyzed.

We extracted spatial data of crashes in Spencer city from the Iowa statewide crash data using the ST_Intersects function provided by the PostGIS extension to clip the intersection-related crashes within the Spencer city boundary. A total of 1149 intersection-related crashes occurred in Spencer city, as shown in Figure 8.

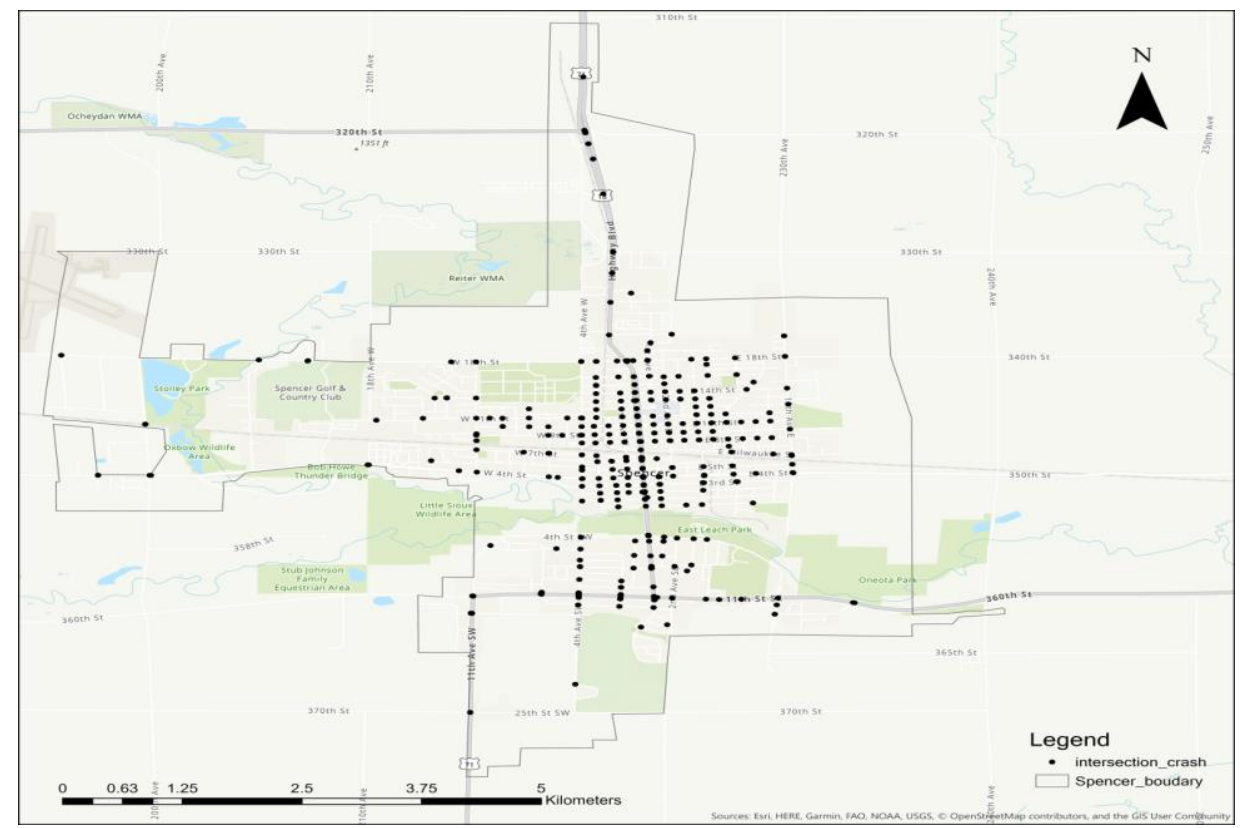

Figure 8. Distribution of crashes in Spencer city. 
Note that it is difficult to determine the crash hotspot intersections from the figure above because there are several overlapping coordinates of crashes. Therefore, the proposed approach is needed to identify the crash hotspot intersections (CHIs).

\section{Results and Discussion}

\subsection{Results}

\subsubsection{The INDSWMI of Spencer City}

As described earlier, the SWM is the critical input parameter for hotspot analysis. Therefore, it was necessary to establish the INDSWMI of Spencer city to accurately express the spatial relationships between intersections.

The spatial weights $\left(W_{i j}\right)$ of the INDSWMI were calculated based on the network shortest distance along the road segments, as discussed in Section 2.3.1. We take the typical T-intersections and cross-intersections shown in Figure 9 as an example to evaluate the intersection extraction algorithm and demonstrate the INDSWMI of Spencer city.

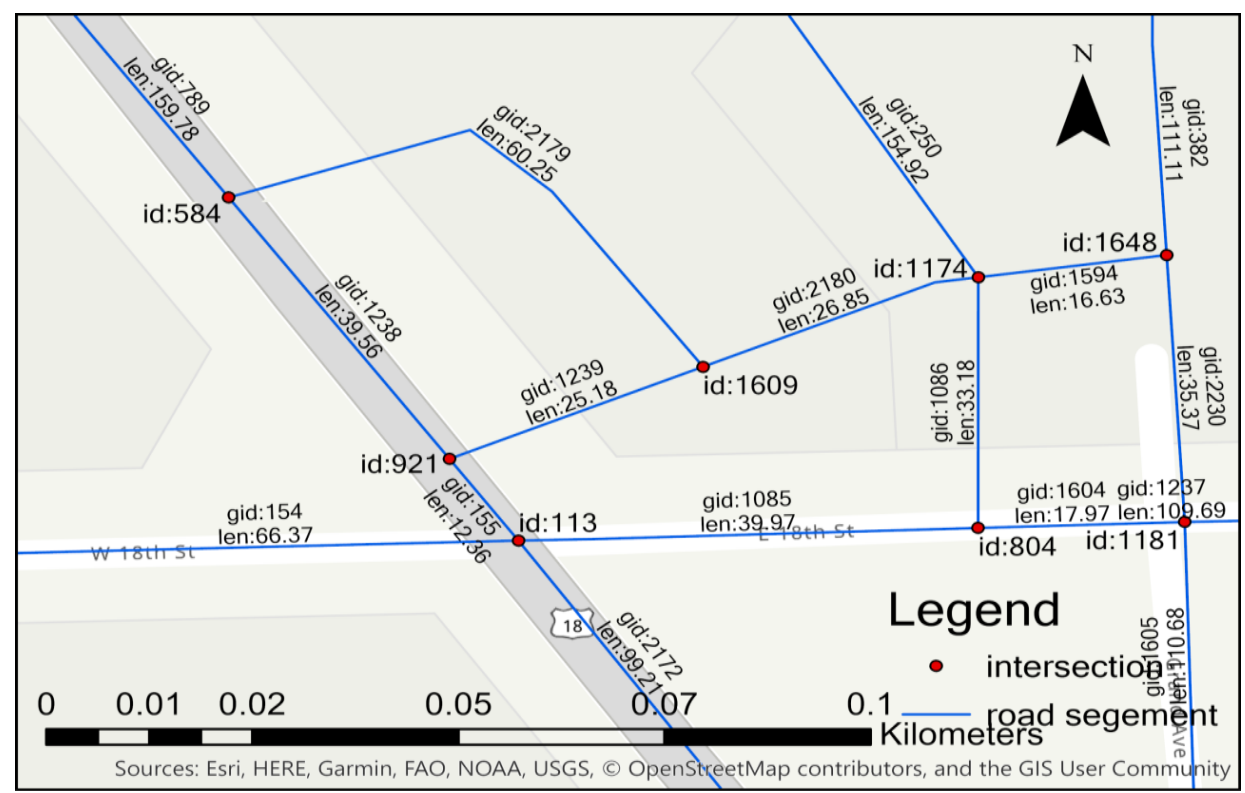

Figure 9. Typical T-intersections and cross-intersections.

We used the geometric method ST_Intersection, provided by the PostGIS extension, to evaluate the intersection extraction algorithm based on road network topological relationships. When all intersections coincide with the coordinates of the collisions using the geometric method, the accuracy of the intersection extraction algorithm can be verified. We took a typical T-intersection (ID. 921) as an example to demonstrate the evaluation results of the intersection extraction algorithm using the geometric method, as shown in Table 2 . The evaluation results successfully demonstrate that the intersection extraction algorithm accurately extracts intersections. 
Table 2. The evaluation results of the intersection extraction algorithm.

\begin{tabular}{|c|c|c|c|c|}
\hline $\begin{array}{l}\text { Intersection id } \\
\text { and Coordinates }\end{array}$ & $\begin{array}{l}\text { Adjacent Road Segment } \\
\text { id and Coordinates }\end{array}$ & $\begin{array}{c}\text { Collision id } \\
\text { and Coordinates }\end{array}$ & $\begin{array}{c}\text { Euclidean } \\
\text { Distance }\end{array}$ & Coincidence \\
\hline \multirow[t]{3}{*}{$\begin{array}{c}\text { id:921 } \\
\text { point }(-95.1464002 \\
43.155801)\end{array}$} & $\begin{array}{c}\text { id:155 } \\
\text { linestring }(-95.1464002 \\
43.155801 \\
-95.146326643 .1557037)\end{array}$ & $\begin{array}{c}\text { Collision }(155,1238) \\
\text { Point }(-95.1464002 \\
43.155801)\end{array}$ & 0 & $\sqrt{ }$ \\
\hline & $\begin{array}{c}\text { id:1238 } \\
\text { linestring }(-95.146636 \\
43.1561124 \\
-95.146400243 .155801)\end{array}$ & $\begin{array}{c}\text { Collision }(155,1239) \\
\text { Point }(-95.1464002 \\
43.155801)\end{array}$ & 0 & $\sqrt{ }$ \\
\hline & $\begin{array}{c}\mathrm{id}: 1239 \\
\text { linestring }(-95.1461293 \\
43.1559108 \\
-95.146400243 .155801)\end{array}$ & $\begin{array}{c}\text { Collision } \\
(1238,1239) \\
\text { Point }(-95.1464002 \\
43.155801)\end{array}$ & 0 & $\sqrt{ }$ \\
\hline
\end{tabular}

According to a suggestion by Getis and Aldstadt [29], a distance band of $683.64 \mathrm{~m}$ was selected to ensure that each intersection had at least one neighbor. Note that the suggestion that each intersection should have at least one neighbor is one of the best-practice guidelines for Getis-Ord $\mathrm{Gi}^{*}$ analysis and has been applied to a vast majority of scenarios. However, our distance band of $683.64 \mathrm{~m}$ is the result of following the above suggestion for the study area in this research. Therefore, this distance band is not applicable universally and should be adjusted accordingly for different scenarios. Table 3 lists the results under a distance band of $683.64 \mathrm{~m}$, including T-intersections (ID. 584, 921, 1609) and cross-intersections (ID. 113, 1174), created by the INDSWMI generation algorithm (discussed in Section 2.3.2) to save intersections' spatial relationships. Note that Table 3 does not list all the neighbors of intersections (for example, intersection 113 has 97 neighbors under a distance band of $683.64 \mathrm{~m}$ ) due to space limitations. Generally, the spatial weights $\left(W_{i j}\right)$ of the INDSWMI were network distance inverted (for example, $W_{113,584}=0.019263$ when the network distance between intersections 113 and 584 is $51.9122 \mathrm{~m}$ ), so nearer intersections have a larger weight than intersections that are farther away. The columns (objectid, gid, nid, row-standardized weight) in Table 3 can be used to generate the binary swm format file, as discussed in Section 2.2.3.

Table 3. The results of the INDSWMI generation algorithm.

\begin{tabular}{|c|c|c|c|c|c|}
\hline Objectid & $\begin{array}{c}\text { Gid } \\
\text { (Intersection i) }\end{array}$ & $\begin{array}{c}\text { Nid } \\
\text { (Intersection } \mathrm{j})\end{array}$ & $\begin{array}{c}\text { Weight } \\
\text { (Row-Standardized) }\end{array}$ & $\begin{array}{l}\text { Weight } \\
\left(1 / \mathbf{n d}_{\mathbf{i j}}\right)\end{array}$ & $\begin{array}{l}\mathrm{nd}_{\mathrm{ij}} \\
(\mathrm{m})\end{array}$ \\
\hline 1 & 113 & 584 & 0.042195 & 0.019263 & 51.9122 \\
\hline 2 & 113 & 921 & 0.177271 & 0.080929 & 12.3565 \\
\hline 3 & 113 & 1174 & 0.034016 & 0.015529 & 64.394 \\
\hline 4 & 113 & 1609 & 0.058348 & 0.026637 & 37.5413 \\
\hline 5 & 584 & 113 & 0.060827 & 0.019263 & 51.9122 \\
\hline 6 & 584 & 921 & 0.079828 & 0.025281 & 39.5557 \\
\hline 7 & 584 & 1174 & 0.036251 & 0.011481 & 87.1041 \\
\hline 8 & 584 & 1609 & 0.052408 & 0.016597 & 60.2514 \\
\hline 9 & 921 & 113 & 0.175461 & 0.080929 & 12.3565 \\
\hline 10 & 921 & 584 & 0.054811 & 0.025281 & 39.5557 \\
\hline 11 & 921 & 1174 & 0.041664 & 0.019217 & 52.0375 \\
\hline 12 & 921 & 1609 & 0.086087 & 0.039706 & 25.1848 \\
\hline 13 & 1174 & 113 & 0.03666 & 0.015529 & 64.394 \\
\hline 14 & 1174 & 584 & 0.027102 & 0.011481 & 87.1041 \\
\hline 15 & 1174 & 921 & 0.045365 & 0.019217 & 52.0375 \\
\hline 16 & 1174 & 1609 & 0.087912 & 0.03724 & 26.8527 \\
\hline 17 & 1609 & 113 & 0.066423 & 0.026637 & 37.5413 \\
\hline 18 & 1609 & 584 & 0.041387 & 0.016597 & 60.2514 \\
\hline 19 & 1609 & 921 & 0.099012 & 0.039706 & 25.1848 \\
\hline 20 & 1609 & 1174 & 0.092862 & 0.03724 & 26.8527 \\
\hline
\end{tabular}


Note that the INDSWMI is a sparse matrix with a large amount of zero $W_{i j}$ data when the network distance between intersections $i, j$ is greater than the distance band. Therefore, in this paper, the rows with a spatial weight of 0 were omitted since the default setting for spatial weights is 0 in hotspot analysis; this can effectively reduce the required file storage space.

\subsubsection{The Results of Intersection Hotspot Analysis (Getis-Ord Gi*) of Spencer City}

We used intersection hotspot analysis (IHA, as discussed in Section 2.3.3) based on geo-processing tools in ArcGIS by taking the input parameters listed in Table 4 to calculate the Getis-Ord $\mathrm{Gi}^{*}, z$-score, $p$-value, and $\mathrm{Gi}^{*}$-bin (confidence level bin) for each intersection to identify the CHIs of Spencer city (2008-2014). Note that the "Distance Band", "Weights Matrix File", and "Input Field," as the key input parameters, were generated in Sections 2.3.1 and 2.3.2.

Table 4. Input parameters of intersection hotspot analysis.

\begin{tabular}{cc}
\hline Input Parameter & Input Value \\
\hline Input Feature Class & intersection \\
Input Field & num_crash \\
Output Feature Class & c: $\backslash$ data $\backslash$ crash_hotspot_intersections.shp \\
get_spatial_weights_from_file \\
true \\
Conceptualization of Spatial Relationships & 683.64 \\
Standardization & c: $\backslash$ data $\backslash$ INDSWMI.swm \\
Distance Band or Threshold Distance & no_fdr \\
Weights Matrix File & \\
Apply False Discovery Rate Correction &
\end{tabular}

In general, when the confidence level exceeds $95 \%$, we consider it to have significant statistical significance. As discussed in Section 2.3.3, we formed a randomization null hypothesis about the spatial distribution of the number of crashes at intersections. If an intersection's positive $p$-value is $>0.05$ and its $G i^{*} Z$ Score is $>1.96$, then the spatial distribution pattern of the number of crashes on the intersection is a random distribution with a probability of less than $5 \%$, and the spatial distribution on the intersection is clustered (positive correlation, hot spot) with a probability of greater than $95 \%$. An intersection that meets the above conditions is considered a $\mathrm{CHI}$ at the $95 \%$ confidence level. From this perspective, we can identify the CHIs that indicate a positive spatial autocorrelation of the number of crashes. The intersections among the CHIs all have a high frequency of crashes, and their neighbor intersections also have a high frequency of crashes. The calculated Gi ${ }^{*} Z S c o r e s$ and $p$-values of CHIs (2008-2014) are listed in Table 5. 
Table 5. Gi*ZScores and $p$-values of intersections in CHIs.

\begin{tabular}{|c|c|c|c|c|c|}
\hline Gid & Name & Num_Crash & Nneighbors & Gi*ZScore & $P$ Value \\
\hline 940 & $\begin{array}{l}\text { S Grand Ave\& S Grand Ave\&11th St } \\
\text { SW\&11th St SE }\end{array}$ & 32 & 45 & 11.275 & 0.000 \\
\hline 1095 & W 44th St\& W 44th St\& Highway Blvd & 32 & 11 & 11.218 & 0.000 \\
\hline 113 & $\begin{array}{l}\text { W 18th St\& Highway Blvd\& W 18th St\& } \\
\text { Highway Blvd }\end{array}$ & 27 & 97 & 9.363 & 0.000 \\
\hline 377 & $\begin{array}{l}\text { W 4th St\& Grand Ave\& Grand Ave\& } \\
\text { E 4th St }\end{array}$ & 26 & 98 & 9.315 & 0.000 \\
\hline 143 & $\begin{array}{l}\text { Grand Ave\& W 8th St\& E 8th St\& } \\
\text { Grand Ave }\end{array}$ & 22 & 112 & 7.806 & 0.000 \\
\hline 1620 & 11th St SW\&7th Ave SW\&\&11th St SW & 22 & 89 & 7.594 & 0.000 \\
\hline 263 & $\begin{array}{l}\text { Grand Ave\& E 7th St\& Grand Ave\& } \\
\text { W 7th St }\end{array}$ & 20 & 112 & 7.161 & 0.000 \\
\hline 391 & $\begin{array}{l}\text { 4th Ave SW\&11th St SW\&4th Ave SW\& } \\
\text { 11th St SW }\end{array}$ & 19 & 92 & 6.629 & 0.000 \\
\hline 728 & $\begin{array}{l}\text { Grand Ave \&W 9th St\& E 9th St\&Grand } \\
\text { Ave }\end{array}$ & 19 & 108 & 6.729 & 0.000 \\
\hline 540 & Grand Ave\& W 1st St\& Grand Ave\& E 1st St & 17 & 83 & 6.002 & 0.000 \\
\hline 1218 & $\begin{array}{l}\text { 11th Ave SW\&13th St SW\&11th Ave } \\
\text { SW\&13th St SW\&11th Ave SW }\end{array}$ & 16 & 51 & 5.447 & 0.000 \\
\hline 358 & $\begin{array}{l}\text { W 11th St\& Grand Ave\& Grand Ave\& } \\
\text { E 11th St }\end{array}$ & 15 & 120 & 5.230 & 0.000 \\
\hline 925 & $\begin{array}{l}\text { S Grand Ave\&4th St SE\& S Grand Ave\& } \\
\text { 4th St SW }\end{array}$ & 15 & 39 & 5.155 & 0.000 \\
\hline 1640 & $\begin{array}{l}\text { Grand Ave\& E 3rd St\& W 3rd St\& } \\
\text { Grand Ave }\end{array}$ & 14 & 92 & 5.022 & 0.000 \\
\hline 31 & $\begin{array}{l}\text { Grand Ave\& W 5th St\& E 5th St\& } \\
\text { Grand Ave }\end{array}$ & 12 & 103 & 4.308 & 0.000 \\
\hline 882 & $\begin{array}{l}\text { W 13th St\& Grand Ave\& E 13th St\& } \\
\text { Grand Ave }\end{array}$ & 10 & 127 & 3.432 & 0.001 \\
\hline 995 & $\begin{array}{l}\text { E 2nd St\& Grand Ave\& W 2nd St\& } \\
\text { Grand Ave }\end{array}$ & 10 & 89 & 3.558 & 0.000 \\
\hline 1100 & 1st Ave E\& E 3rd St\& E 3rd St\&1st Ave E & 10 & 89 & 3.508 & 0.000 \\
\hline 918 & 8th St SW\& S Grand Ave\& S Grand Ave & 8 & 47 & 2.642 & 0.008 \\
\hline 1153 & E 4th St\&4th Ave E\& E 4th St\&4th Ave E & 8 & 79 & 2.670 & 0.008 \\
\hline 1515 & 4th Ave E\& E 8th St\&4th Ave E\& E 8th St & 8 & 114 & 2.680 & 0.007 \\
\hline 1538 & 3rd Ave E\& E 9th St\&3rd Ave E\& E 9th St & 8 & 111 & 2.696 & 0.007 \\
\hline 1561 & $\begin{array}{l}\text { 2nd Ave SE\&11th St SE\&11th St SE\& } \\
\text { 2nd Ave SE }\end{array}$ & 8 & 43 & 2.671 & 0.008 \\
\hline 270 & $\begin{array}{l}\text { E 10th St\&6th Ave E\& E 10th St\& } \\
\text { Fairview Ave }\end{array}$ & 7 & 111 & 2.248 & 0.025 \\
\hline 1152 & E 4th St\& E 4th St\&1st Ave E & 7 & 87 & 2.298 & 0.022 \\
\hline 187 & 1st Ave E\& E 2nd St\&1st Ave E\& E 2nd St & 6 & 86 & 2.058 & 0.040 \\
\hline 538 & $\begin{array}{l}\text { E Park St\& Grand Ave\& W Park St\& } \\
\text { Grand Ave }\end{array}$ & 6 & 70 & 2.047 & 0.041 \\
\hline 720 & $\begin{array}{l}\text { W 10th St\& Grand Ave\& E 10th St\& } \\
\text { Grand Ave }\end{array}$ & 6 & 116 & 2.079 & 0.038 \\
\hline 1455 & $\begin{array}{l}\text { 1st Ave W\& W 7th St\&1st Avenue W\& } \\
\text { W 7th St }\end{array}$ & 6 & 104 & 2.081 & 0.037 \\
\hline
\end{tabular}

Furthermore, the expected $\mathrm{Gi}^{*} \mathrm{ZS}$ core has a positive correlation with the number of crashes for each intersection. Based on the linear regression, we used the number of crashes as independent variable $x$ and the Gi*ZScore as independent variable $y$ in the output feature shapefile to draw a scatter plot, shown in Figure 10. The scatter plot indicates that there is a linear relationship between the number of crashes and the $\mathrm{G}_{\mathrm{i}}{ }^{\mathrm{Z}} \mathrm{ZScore}$.

The CHIs in the output feature shapefile of IHA at the $95 \%$ confidence level are colored in red in Figure 11 using GIS visualization. Figure 11 clearly demonstrates that the $\mathrm{CHIs}$ are clustered along the roads including Grand Ave, S Grand Ave, 11th St SE, and 1st Ave E. Based on the spatial distribution of $\mathrm{CHIs}$, transportation authorities can develop targeted mitigation strategies to effectively reduce the number of crashes. 


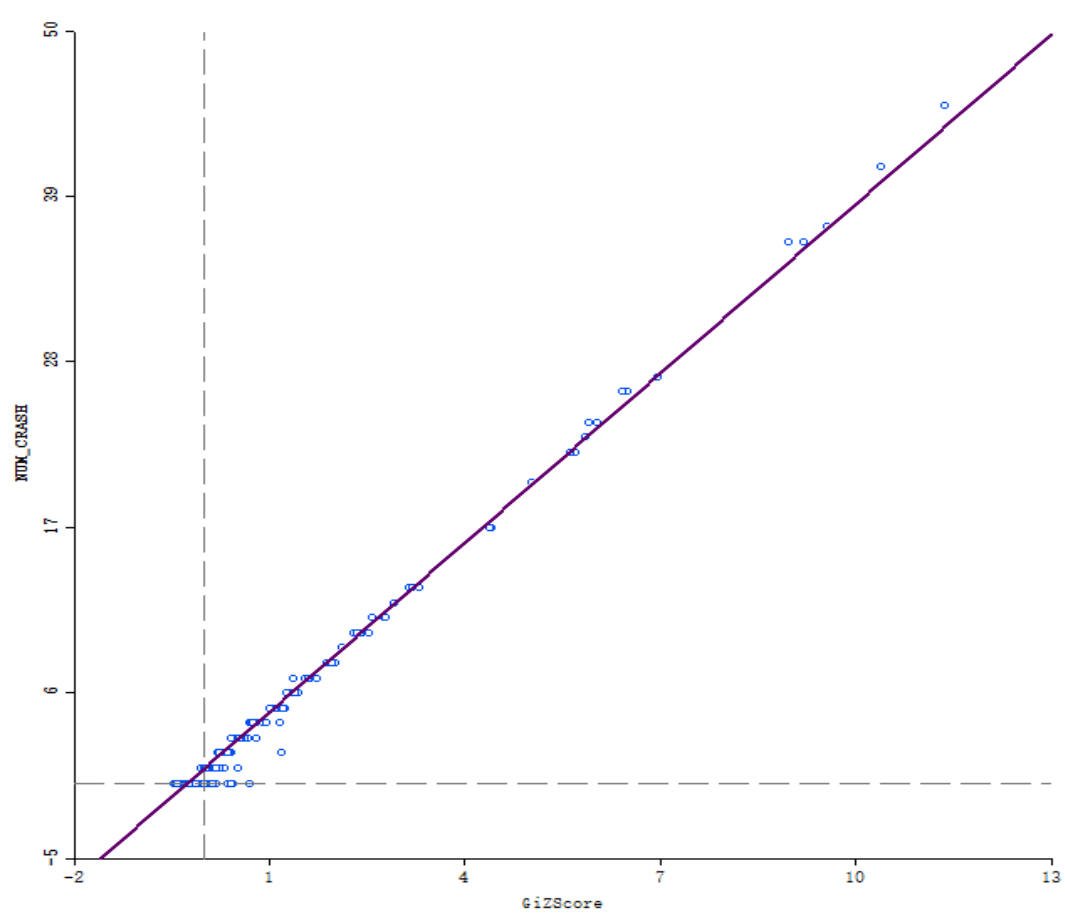

Figure 10. Linear regression between the number of crashes and the Gi*ZScore.

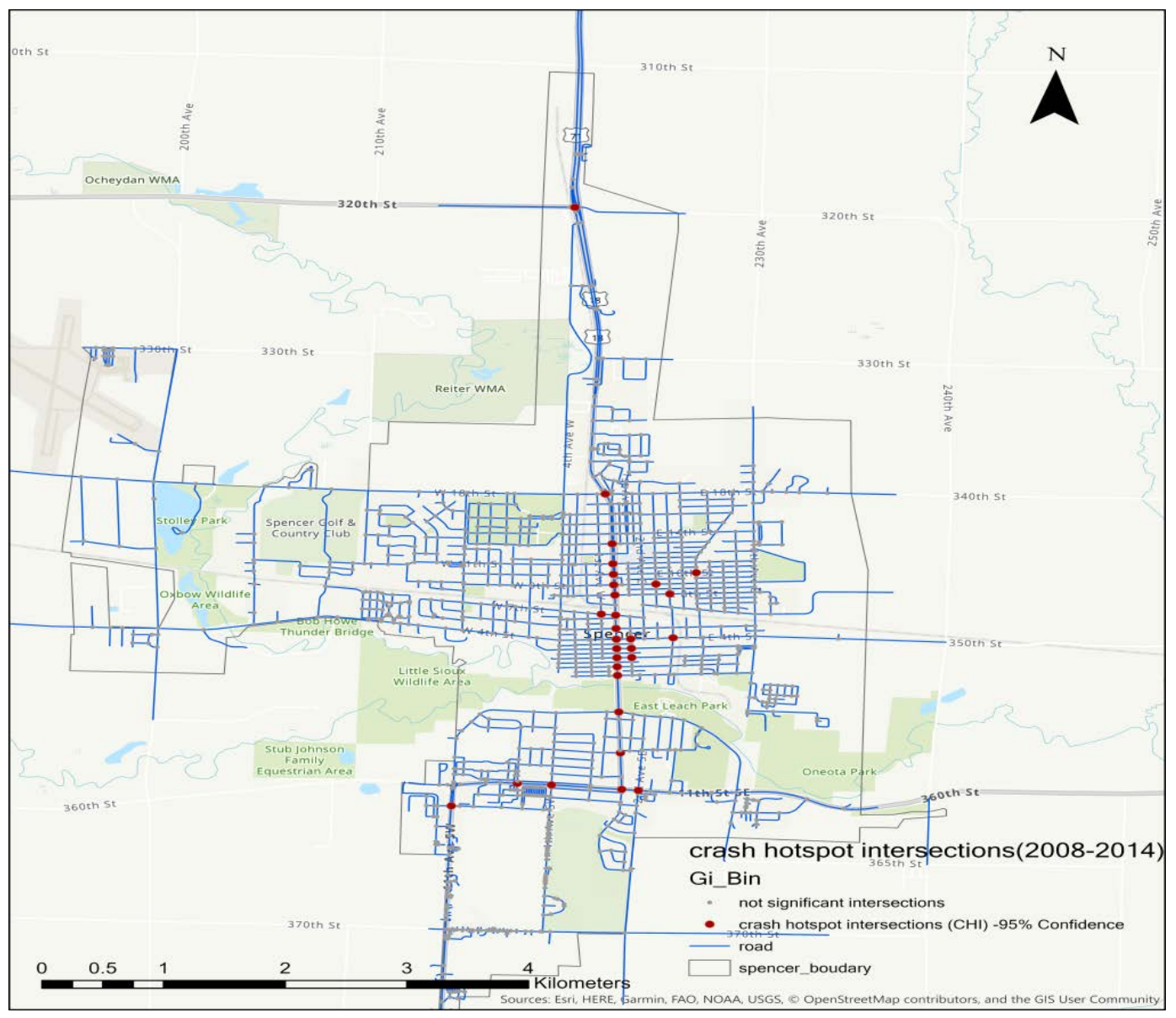

Figure 11. Distribution of crash hotspot intersections in Spencer city. 


\subsection{A Performance Comparison of IHA between INDSWMI and IEDSWMI}

As discussed in Section 2.3.1, the inverse Euclidean distance-band spatial weights matrix of intersections (IEDSWMI) can also be used in IHA. Further experimentation of IHA comparing the GIS visualization and Intersection Prediction Accuracy Index (IPAI, as discussed in Section 2.3.3) between the INDSWMI and IEDSWMI was discussed to validate the performance of the proposed approach.

The crash data of Spencer city for 2008-2014 were used as the training data in the IHA, and the crash data of Spencer city for 2015-2017 were used as the test data in the IPAI calculation. Note that the training and test crash data were both applied in the KDSWMCI generation algorithm to statistically analyze the number of crashes separately. To be more specific, the number of crashes in 2008-2014 at each intersection was used as the training data to identify CHIs. Then, the number of crashes in 2015-2017 at intersections which were within these CHIs was used as the test data to calculate the IPAI. By this approach, the same datasets and the same parameters (as shown in Table 4), except the weights matrix files (INDSWMI and IEDSWMI), were implemented in intersection hotspot analysis at the $95 \%$ confidence level, and the IPAI was then measured.

To contrast them, Figure 12 shows the results of intersection hotspot analysis for the INDSWMI (Figure 12a) and IEDSWMI (Figure 12b). By comparing Figure 12a,b, we can see that the intersection distribution pattern of the CHIs is slightly different. There are fewer CHIs in Figure 11a than in Figure $12 \mathrm{~b}$. However, the distribution pattern of roads within the CHIs is notably different. There are much fewer roads within CHIs in Figure 12a than in Figure 12b, which means that the CHIs in Figure 12a have stronger spatial aggregation than those in Figure 12b. These differences are expected since the road network distance of intersections is more appropriate as a distance measurement than the Euclidean distance for IHA.

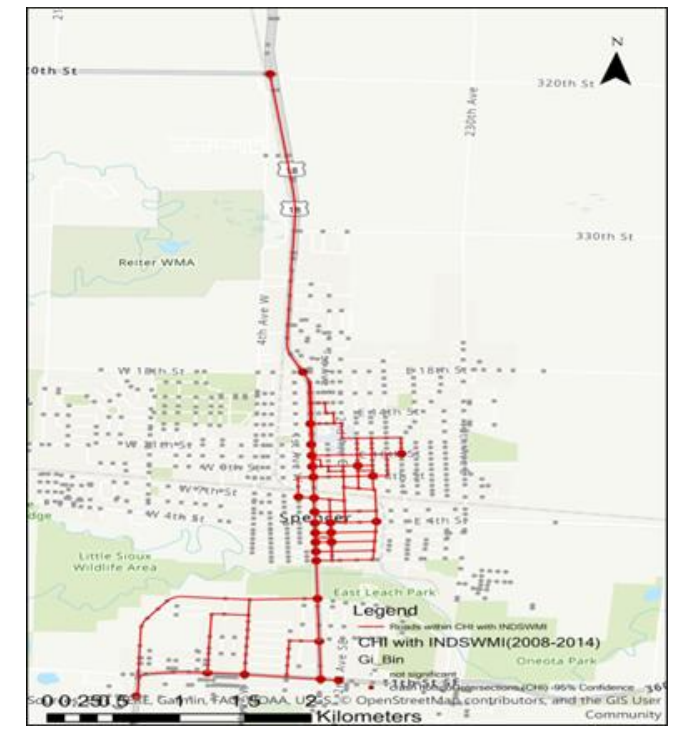

(a) The result of IHA with INDSWMI.

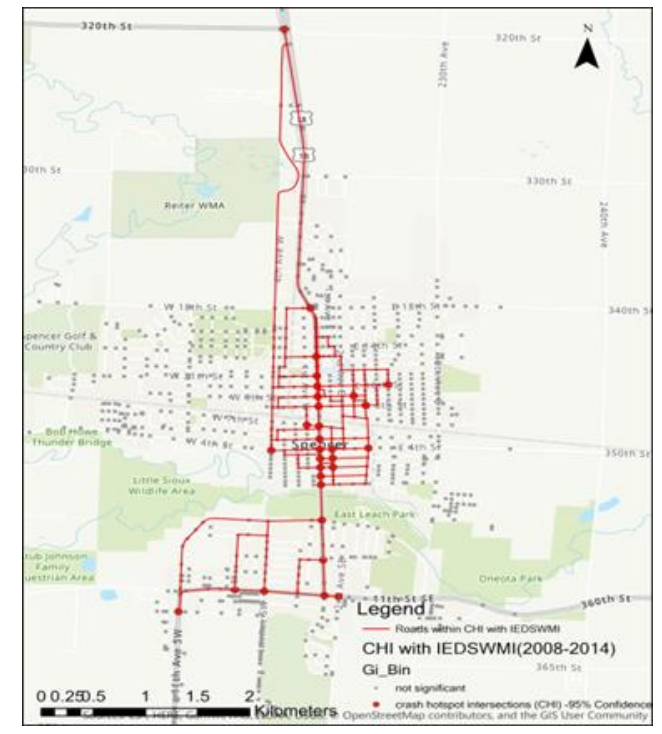

(b) The result of IHA with IEDSWMI.

Figure 12. Visual comparison of IHA using the INDSWMI and IEDSWMI.

Note that the above visual comparison can only qualitatively validate the performance of the proposed approach. In order to quantitatively validate the performance of the proposed approach, the IPAI values of IHA using the INDSWMI and IEDSWMI should be compared. In theory, the higher the IPAI, the better the CHI prediction performance of the approach. The calculated IPAI results, shown in Table 6, indicate that higher prediction accuracy was achieved by IHA with the INDSWMI (IPAI: 4.79) than by IHA with the IEDSWMI (IPAI: 3.45). 
Table 6. The IPAI and the percentage of CHIs predicted.

\begin{tabular}{|c|c|c|c|c|c|c|c|}
\hline & $\begin{array}{l}\text { Number } \\
\text { of Crashes } \\
\text { in CHIs } \\
(2008-2014)\end{array}$ & $\begin{array}{l}\text { Percentage } \\
\text { of Crashes } \\
\text { in CHIs } \\
(2008-2014)\end{array}$ & $\begin{array}{l}\text { Number } \\
\text { of Crashes } \\
\text { in CHIs } \\
(2015-2017)\end{array}$ & $\begin{array}{l}\text { Percentage } \\
\text { of Crashes } \\
\text { in CHIs } \\
(2015-2017)\end{array}$ & $\begin{array}{l}\text { Total Length } \\
\text { of Roads } \\
\text { within } \\
\text { CHIs (m) }\end{array}$ & $\begin{array}{c}\text { Percentage } \\
\text { of Total Length } \\
\text { of Roads } \\
\text { within CHIs }\end{array}$ & IPAI \\
\hline $\begin{array}{l}\text { IHA with } \\
\text { INDSWMI }\end{array}$ & 29 & $51.68 \%$ & 137 & $47.90 \%$ & $24,115.51$ & $10.01 \%$ & 4.79 \\
\hline $\begin{array}{l}\text { IHA with } \\
\text { IEDSWMI }\end{array}$ & 30 & $52.42 \%$ & 140 & $48.95 \%$ & $34,198.16$ & $14.19 \%$ & 3.45 \\
\hline
\end{tabular}

Furthermore, an interesting result is indicated: the predicted percentage of crashes in CHIs during 2015-2017 is similar to the identified percentage of crashes in CHIs during 2008-2014 in both IHA with INDSWMI (51.68\%-47.90\%) and IHA with IEDSWMI (52.42\%-48.95\%). From this perspective, the results reveal that the CHIs which are identified by this approach have a high probability of being intersections with a high frequency of crashes in the future.

\section{Conclusions}

Intersections have an important impact on the frequency of crashes. In this paper we successfully demonstrated an approach to directly identify crash hotspot intersections (CHIs) using spatial weights matrices (SWMs). The application of this methodology was illustrated by using a spatial data set, including roads and traffic crashes, of Spencer city, Iowa, USA. The proposed inverse network distance-band spatial weights matrix of intersections (INDSWMI) generation algorithm uses the network distance matrix of intersections (NDMI) and a distance band to conceptualize the spatial relationships between intersections with respect to road network restraints. The developed k-nearest distance-band spatial weights matrix between crash and intersection (KDSWMCI, $\mathrm{k}=1)$ generation algorithm has the ability to aggregate the crashes with intersections by considering GPS location accuracy. The INDSWMI generation algorithm can also be applied to building the SWM of road network crashes with the added value that it can be used to support further spatial analysis (e.g., high-low clustering and Local Moran's I analysis). As a major contribution, we developed the Intersection Prediction Accuracy Index (IPAI) to test the prediction performance of intersection hotspot analysis (IHA). According to the findings of a performance comparison between IHA with the INDSWMI and IHA with the inverse Euclidean distance-band spatial weights matrix of intersections (IEDSWMI), the proposed approach has higher accuracy in identifying CHIs.

The potential of this study can be further realized if we address the following two issues in our future work. First, in this study, the crashes were applied in the proposed approach without consideration of the different crash types. Crashes can be divided into different types-vehicle rollover, single-car accident, rear-end collision, side-impact collision, and head-on collision-and each type may have a different spatial pattern. It is necessary to differentiate the treatment of crashes according to different types. As such, we will develop a spatial data mining approach considering different types of crashes to discover the different spatial patterns of crashes. Second, in the current approach, the IPAI was tested with one distance band chosen to ensure that each intersection had at least one neighbor. However, the selection of a different distance band according to a different minimum neighbor count may have some influence on the prediction accuracy of the proposed approach. As such, in future work we will analyze the prediction accuracy of the IHA with different distance bands and suggest a distance band selection to maximize the prediction performance of the proposed approach.

Author Contributions: Z.Z. and G.S. developed the original idea. Z.Z. and Y.M. proposed the method. Z.Z. and Y.M. analyzed the data. Z.Z. and G.S. wrote the paper. Y.M. proofread and revised the paper. All authors have read and agreed to the published version of the manuscript.

Funding: This work was supported by the Construction Science and Technology Program of Hubei Province in 2016 (Transportation, municipal No. 02) and the Research Start-Up Funding of Hubei University of Education Grant NO. 18RC09. 
Conflicts of Interest: The authors declare no conflict of interest.

\section{References}

1. Federal Highway Administration (US); Federal Transit Administration (US). 2015 Status of the Nation's Highways, Bridges, and Transit Conditions E Performance Report to Congress; Federal Highway Administration (US), Federal Transit Administration (US), Ed.; Government Printing Office: Washington, DC, USA, 2017.

2. Peng, J.; Xiao, L.; Zhang, J.; Cai, C.S.; Wang, L. Flexural behavior of corroded HPS beams. Eng. Struct. 2019, 195, 274-287. [CrossRef]

3. Huo, L.; Li, C.; Jiang, T.; Li, H.-N. Feasibility study of steel bar corrosion monitoring using a piezoceramic transducer enabled time reversal method. Appl. Sci. 2018, 8, 2304. [CrossRef]

4. Frangopol, D.M.; Tsompanakis, Y. Maintenance and Safety of Aging Infrastructure; Structures and Infrastructures Series; Frangopol, D.M., Tsompanakis, Y., Eds.; CRC Press: Boca Raton, FL, USA; Leiden, The Netherlands, 2014; ISBN 978-0-415-65942-0.

5. Zhu, J.; Ho, S.C.M.; Kong, Q.; Patil, D.; Mo, Y.-L.; Song, G. Estimation of impact location on concrete column. Smart Mater. Struct. 2017, 26, 055037. [CrossRef]

6. Qi, B.; Kong, Q.; Qian, H.; Patil, D.; Lim, I.; Li, M.; Liu, D.; Song, G. Study of impact damage in pva-ecc beam under low-velocity impact loading using piezoceramic transducers and pvdf thin-film transducers. Sensors 2018, 18, 671. [CrossRef]

7. Yin, X.; Song, G.; Liu, Y. Vibration suppression of wind/traffic/bridge coupled system using Multiple Pounding Tuned Mass Dampers (MPTMD). Sensors 2019, 19, 1133. [CrossRef]

8. Kong, Q.; Robert, R.; Silva, P.; Mo, Y. Cyclic crack monitoring of a reinforced concrete column under simulated pseudo-dynamic loading using piezoceramic-based smart aggregates. Appl. Sci. 2016, 6, 341. [CrossRef]

9. Liu, Y.; Zhang, M.; Yin, X.; Huang, Z.; Wang, L. Debonding detection of reinforced concrete (RC) beam with near-surface mounted (NSM) pre-stressed carbon fiber reinforced polymer (CFRP) plates using embedded piezoceramic smart aggregates (SAs). Appl. Sci. 2019, 10, 50. [CrossRef]

10. Li, N.; Wang, F.; Song, G. New entropy-based vibro-acoustic modulation method for metal fatigue crack detection: An exploratory study. Measurement 2020, 150, 107075. [CrossRef]

11. Du, B.; Huang, R.; Chen, X.; Xie, Z.; Liang, Y.; Lv, W.; Ma, J. Active CTDaaS: A data service framework based on transparent iod in city traffic. IEEE Trans. Comput. 2016, 1. [CrossRef]

12. Wang, H.; Wu, X.; Sun, L.; Du, B. Passenger behavior prediction with semantic and multi-pattern LSTM model. IEEE Access 2019, 7, 157873-157882. [CrossRef]

13. 2017 Quick Facts. Available online: https://crashstats.nhtsa.dot.gov/ (accessed on 19 February 2020).

14. Iowa Department of Transportation's Public Platform. Available online: https://data.iowadot.gov/ (accessed on 20 December 2019).

15. Achu, A.L.; Aju, C.D.; Suresh, V.; Manoharan, T.P.; Reghunath, R. Spatio-temporal analysis of road accident incidents and delineation of hotspots using geospatial tools in Thrissur District, Kerala, India. Kn J. Cartogr. Geogr. Inf. 2019, 69, 255-265. [CrossRef]

16. Getis, A.; Ord, J.K. The analysis of spatial association by use of distance statistics. Geogr. Anal. 2010, 24, 189-206. [CrossRef]

17. Ulak, M.B.; Ozguven, E.E.; Vanli, O.A.; Horner, M.W. Exploring alternative spatial weights to detect crash hotspots. Comput. Environ. Urban Syst. 2019, 78, 101398. [CrossRef]

18. Ouni, F.; Belloumi, M. Pattern of road traffic crash hot zones versus probable hot zones in Tunisia: A geospatial analysis. Accid. Anal. Prev. 2019, 128, 185-196. [CrossRef] [PubMed]

19. Khan, G.; Qin, X.; Noyce, D.A. Spatial analysis of weather crash patterns. J. Transp. Eng. 2008, 134, $191-202$. [CrossRef]

20. Prasannakumar, V.; Vijith, H.; Charutha, R.; Geetha, N. Spatio-temporal clustering of road accidents: Gis based analysis and assessment. Procedia Soc. Behav. Sci. 2011, 21, 317-325. [CrossRef]

21. Erdogan, S.; Ilçi, V.; Soysal, O.M.; Kormaz, A. A model suggestion for the determination of the traffic accident hotspots on the turkish highway road network: A pilot study. Bulletin of Geodetic Sciences. 2015, 21, 169-188. [CrossRef] 
22. Kuo, P.-F.; Zeng, X. Guidelines for choosing hot-spot analysis tools based on data characteristics, network restrictions, and time distributions. In Proceedings of the 91st Annual Meeting of the Transportation Research Board, Washington, DC, USA, 22-26 January 2012; pp. 22-26.

23. Zahran, E.-S.M.M.; Tan, S.J.; Tan, E.H.A.; Mohamad'Asri Putra, N.A.A.B.; Yap, Y.H.; Abdul Rahman, E.K. Spatial analysis of road traffic accident hotspots: Evaluation and validation of recent approaches using road safety audit. J. Transp. Saf. Secur. 2019, 1-30. [CrossRef]

24. Colak, H.E.; Memisoglu, T.; Erbas, Y.S.; Bediroglu, S. Hot spot analysis based on network spatial weights to determine spatial statistics of traffic accidents in Rize, Turkey. Arab. J. Geosci. 2018, 11, 151. [CrossRef]

25. Mitra, S. Spatial autocorrelation and bayesian spatial statistical method for analyzing intersections prone to injury crashes. Transp. Res. Rec. 2009, 2136, 92-100. [CrossRef]

26. Cheng, Z.; Zu, Z.; Lu, J. Traffic crash evolution characteristic analysis and spatiotemporal hotspot identification of urban road intersections. Sustainability 2018, 11, 160. [CrossRef]

27. Cinnamon, J.; Schuurman, N.; Hameed, S.M. Pedestrian injury and human behaviour: Observing road-rule violations at high-incident intersections. PLoS ONE 2011, 6, e21063. [CrossRef] [PubMed]

28. Getis, A. Spatial weights matrices: Spatial weights matrices. Geogr. Anal. 2009, 41, 404-410. [CrossRef]

29. Getis, A.; Aldstadt, J. Constructing the spatial weights matrix using a local statistic. Geogr. Anal. 2004, 36, 90-104. [CrossRef]

30. Zhang, R.; Du, Q.; Geng, J.; Liu, B.; Huang, Y. An improved spatial error model for the mass appraisal of commercial real estate based on spatial analysis: Shenzhen as a case study. Habitat Int. 2015, 46, 196-205. [CrossRef]

31. Zhang, Z.; Ming, Y.; Song, G. Identify road clusters with high-frequency crashes using spatial data mining approach. Appl. Sci. 2019, 9, 5282. [CrossRef]

32. Jun, M.-J.; Kim, H.-J. Measuring the effect of greenbelt proximity on apartment rents in Seoul. Cities 2017, 62, 10-22. [CrossRef]

33. Chen, J.; Fu, J.; Zhang, M. An atmospheric correction algorithm for landsat/tm imagery basing on inverse distance spatial interpolation algorithm: A case study in taihu lake. IEEE J. Sel. Top. Appl. Earth Obs. Remote Sens. 2011, 4, 882-889. [CrossRef]

34. Kataria, A.; Singh, M.D. A review of data classification using k-nearest neighbour algorithm. Int. J. Emerg. Technol. Adv. Eng. 2013, 3, 7.

35. Graser, A. Integrating open spaces into openstreetmap routing graphs for realistic crossing behaviour in pedestrian navigation. GI_Forum 2016 2016, 1, 217-230. [CrossRef]

36. Mocnik, F.-B.; Mobasheri, A.; Zipf, A. Open source data mining infrastructure for exploring and analysing OpenStreetMap. Open Geospat. Data Softw. Stand. 2018, 3, 7. [CrossRef]

37. García, F.; García, J.; Ponz, A.; de la Escalera, A.; Armingol, J.M. Context aided pedestrian detection for danger estimation based on laser scanner and computer vision. Expert Syst. Appl. 2014, 41, 6646-6661. [CrossRef]

38. García, F.; Jiménez, F.; Anaya, J.; Armingol, J.; Naranjo, J.; de la Escalera, A. Distributed pedestrian detection alerts based on data fusion with accurate localization. Sensors 2013, 13, 11687-11708. [CrossRef] [PubMed]

39. Fogliaroni, P.; Bucher, D.; Jankovic, N.; Giannopoulos, I. Intersections of our world. LIPIcs 2018, 3, 15.

40. Moerbeek, M. Bayesian evaluation of informative hypotheses in cluster-randomized trials. Behav. Res. 2019, 51, 126-137. [CrossRef] [PubMed]

41. Pelaez, C.G.A.; Garcia, F.; de la Escalera, A.; Armingol, J.M. Driver monitoring based on low-cost 3-d sensors. IEEE Trans. Intell. Transp. Syst. 2014, 15, 1855-1860. [CrossRef]

42. Carmona, J.; García, F.; Martín, D.; Escalera, A.; Armingol, J. Data fusion for driver behaviour analysis. Sensors 2015, 15, 25968-25991. [CrossRef]

43. Agarwal, S.; Rajan, K.S. Performance analysis of MongoDB versus PostGIS/PostGreSQL databases for line intersection and point containment spatial queries. Spat. Inf. Res. 2016, 24, 671-677. [CrossRef]

44. Bucklin, D.; Basille, M. Rpostgis: Linking R with a PostGIS spatial database. $R$ J. 2018, 10, 251. [CrossRef]

45. Tom-Jack, Q.T.; Bernstein, J.M.; Loyola, L.C. The role of geoprocessing in mapping crime using hot streets. IJGI 2019, 8, 540. [CrossRef]

46. Lam, C.; Souza, P.C.L. Estimation and selection of spatial weight matrix in a spatial lag model. J. Bus. Econ. Stat. 2019, 1-41. [CrossRef] 
47. Abokifa, A.A.; Sela, L. Identification of spatial patterns in water distribution pipe failure data using spatial autocorrelation analysis. J. Water Resour. Plann. Manag. 2019, 145, 04019057. [CrossRef]

48. Griffith, D.A.; Paelinck, J.H.P. General conclusions about spatial statistics. In Morphisms for Quantitative Spatial Analysis; Springer International Publishing: Cham, Switzerland, 2018; Volume 51, pp. 113-121.

49. Liu, H.; Wang, J. Vulnerability assessment for cascading failure in the highway traffic system. Sustainability 2018, 10, 2333. [CrossRef]

50. Yu, L.; Jiang, H.; Hua, L. Anti-congestion route planning scheme based on dijkstra algorithm for automatic valet parking system. Appl. Sci. 2019, 9, 5016. [CrossRef]

51. Monteiro, F.R.; Garcia, M.A.P.; Cordeiro, L.C.; de Lima Filho, E.B. Bounded model checking of C++ programs based on the Qt cross-platform framework: BMC of C++ programs based on Qt Cross-Platform Framework. Softw. Test. Verif. Reliab. 2017, 27, e1632. [CrossRef]

52. Wing, M.G.; Eklund, A.; Kellogg, L.D. Consumer-grade global positioning system (gps) accuracy and reliability. J. For. 2005, 103, 169-173. [CrossRef]

53. Manepalli, U.R.R.; Bham, G.H.; Kandada, S. Evaluation of hotspots identification using kernel density estimation (k) and getis-ord ( $\mathrm{gi}^{*}$ ) on i-630. In Proceedings of the 3rd International Conference on Road Safety and Simulation, Indianapolis, IN, USA, 14-16 September 2011; Transportation Research Board of the National Academies: Washington, DC, USA, 2011; p. 17.

54. Anselin, L. Local indicators of spatial association-LISA. Geogr. Anal. 2010, 27, 93-115. [CrossRef]

55. Tobler, W. On the first law of geography: A reply. Ann. Assoc. Am. Geogr. 2004, 94, 304-310. [CrossRef]

56. Songchitruksa, P.; Zeng, X. Getis-Ord spatial statistics to identify hot spots by using incident management data. Transp. Res. Rec. J. Transp. Res. Board 2010, 2165, 42-51. [CrossRef]

57. Benmoussa, A.; Gotti, C.; Bourassa, S.; Gilbert, C.; Provost, P. Identification of protein markers for extracellular vesicle (EV) subsets in cow's milk. J. Proteom. 2019, 192, 78-88. [CrossRef]

58. Chainey, S.; Tompson, L.; Uhlig, S. The utility of hotspot mapping for predicting spatial patterns of crime. Secur. J. 2008, 21, 4-28. [CrossRef]

59. Flaxman, S.; Chirico, M.; Pereira, P.; Loeffler, C. Scalable high-resolution forecasting of sparse spatiotemporal events with kernel methods: A winning solution to the NIJ "Real-Time Crime Forecasting Challenge". Ann. Appl. Stat. 2019, 13, 2564-2585. [CrossRef]

60. Kajita, M.; Kajita, S. Crime prediction by data-driven Green's function method. Int. J. Forecast. 2019. [CrossRef]

61. Thakali, L.; Kwon, T.J.; Fu, L. Identification of crash hotspots using kernel density estimation and kriging methods: A comparison. J. Mod. Transp. 2015, 23, 93-106. [CrossRef]

62. Bell, D.; Jayne, M. Small Cities? Towards a Research Agenda. Int. J. Urban Reg. Res. 2009, 33, 683-699. [CrossRef]

(C) 2020 by the authors. Licensee MDPI, Basel, Switzerland. This article is an open access article distributed under the terms and conditions of the Creative Commons Attribution (CC BY) license (http://creativecommons.org/licenses/by/4.0/). 